Valquíria Pereira Ferreira ${ }^{1}$

Maria Arleide da Silva

Carlos Noronha Neto

Gilliatt Hanois Falbo Neto ${ }^{1}$

Cynthia Vasconcelos Chaves ${ }^{2}$

Rodrigo Pereira Bello ${ }^{2}$

\title{
Prevalência e fatores associados à violência sofrida em mulheres encarceradas por tráfico de drogas no Estado de Pernambuco, Brasil: um estudo transversal
}

Prevalence and factors associated with violence suffered by incarcerated women for drug trafficking in the state of Pernambuco, Brazil: a cross-sectional study

Instituto de Medicina ntegral Prof. Ferna Figueira. R. dos Coelhos 300 , Ilha do Leite. 0.070-490 Recife PE Brasil.

valquiriapf@gmail.com

${ }^{2}$ Faculdade Pernambucana de Saúde.
Abstract The scope of this study was to estimate the prevalence and factors associated with the violence suffered by women accused of drug trafficking in the 24 months prior to incarceration in the Women's Penal Colony in the State of Pernambuco. A cross-sectional study including 290 women aged 18 and above, with up to twelve months imprisonment, was performed for the dato collection period. A questionnaire was applied to research the socioeconomic and demographic variables and the characteristics of violence and drug trafficking. All of the participants signed a consent form. The association between variables and intensity of exposure and response were determined by the chi-square test and the values ( $p<$ 0.05 ) were considered statistically significant. The study revealed that $71.4 \%$ of women were young; 78.9\% non white, $85.8 \%$ unmarried with children, $83.3 \%$ had low education and $72.6 \%$ had income below the minimum wage. Furthermore, $56.9 \%$ were users of illicit drugs and $67.5 \%$ participated by performing some role in drug trafficking. A high prevalence of some form of violence suffered were observed in the population studied and the partner was the most frequent perpetrator $(44.1 \%)$, calling for the authorities to pay greater attention in the actions of prevention of such violence.

Key words Violence against women, Prevalence, Illicit drugs, Prisons
Resumo Este estudo objetivou estimar a prevalência e os fatores associados à violência sofrida nos 24 meses anteriores ao encarceramento de mulheres por tráfico de drogas em Colônia Penal Feminina no Estado de Pernambuco. Realizou-se um estudo de corte transversal incluindo $290 \mathrm{mu}$ lheres com 18 ou mais anos de idade e com até doze meses de encarceramento no período da coleta de dados. Utilizou-se como instrumento um questionário pesquisando variáveis socioeconômicas e demográficas e características da violência e do tráfico de drogas. Todas as participantes assinaram o Termo de Consentimento Livre e Esclarecido. A associação e a intensidade entre as variáveis de exposição e resposta foram determinadas pelo teste qui-quadrado e valores $(p<0,05)$ considerados estatisticamente significantes. $O$ estudo mostrou que $71,4 \%$ das mulheres eram jovens; $78,9 \%$ não brancas; $85,8 \%$ solteiras com filhos; $83,3 \%$ tinham baixa escolaridade e 72,6\% recebiam renda inferior ao salário mínimo. Usaram drogas ilícitas $47,3 \%$ e desenvolveram algum papel no tráfico de drogas 67,5\%. Prevalências elevadas para algum tipo de violência sofrida foram observadas na população estudada e o companheiro foi identificado como perpetrador mais frequente $(44,1 \%)$, sugerindo maior atenção das autoridades nas ações de prevenção desses agravos.

Palavras-chave Violência contra a mulher, Prevalência, Drogas ilícitas, Prisões 


\section{Introdução}

Historicamente, a violência contra a mulher é um fenômeno universal que atinge todas as classes sociais, etnias, religiões, culturas e independe do nível de desenvolvimento socioeconômico da população vitimizada ${ }^{1}$. Embora seja um tema remetido ao campo da saúde pública, embasado na constatação crescente de que a violência de gênero está associada a um maior risco para diversos agravos à saúde física e mental, trauma físico direto e uso mais frequente dos serviços de saúde, vários estudos revelam que a situação das mulheres continua marcada por graves violações aos direitos humanos, necessitando de particular atençãa ${ }^{2-6}$.

As desigualdades de gênero, determinantes das relações violentas que se constituem no âmbito familiar, mostram que em muitas situações a violência física se faz acompanhar pela coerção psicológica e o abuso sexual ${ }^{7}$. Estudos sobre abusos sofridos e presenciados na infância e adolescência, destacam a violência nas relações familiares como um fator que pode favorecer o abandono do lar pelos adolescentes, início precoce da vida sexual, aceitação de sofrer violência ou praticá-la como conduta adequada e maior propensão para a prostituição e o uso de drogas lícitas e ilícitas ${ }^{8,9}$.

A transgeracionalidade da violência gera custos para o setor de saúde, pois além dos danos físicos e psicológicos às mulheres, implica em riscos para seus descendentes. Presenciando a violência familiar, incrementa-se nos(as) filhos(as) as probabilidades de sofrer depressão, ansiedade, transtornos de conduta, além de aumentar o risco de se converterem em vítimas de maus-tratos ou futuros agressores 8 .

Em um contexto mais amplo, a violência provoca perdas importantes. Estudo realizado em Recife (PE), incluindo os anos de 2003 a 2007, encontrou 43,3 Anos Potenciais de Vida Perdidos (APVP) por cada vítima de homicídio, no período, na cidade do Recife, capital do Estado de Pernambuco, considerando o limite máximo de 70 anos de idade estabelecido pelo Ministério da Saúde ${ }^{10}$.

Em relação à participação feminina na criminalidade, estudos brasileiros mostram que essa pode estar associada à influência do meio sociocultural da mulher e que essa população tende a ser jovem, de baixa escolaridade e nível socioeconômico, com história de prostituição e envolvimento com o tráfico de drogas ${ }^{11,12}$.

Embora apresente índices menos elevados se comparados à participação do sexo masculino, a delinquência feminina no Brasil é crescente e tem se tornado um problema emblemático contemporâneo. Dados do Departamento Penitenciário Nacional (DEPEN) evidenciaram que a população carcerária feminina cresceu $12,0 \%$ nos últimos cinco anos. O tráfico de drogas foi responsável por $62,4 \%$ do encarceramento de mulheres no Brasil no mesmo período ${ }^{13}$.

Fatores como parentes no tráfico, facilidade de acesso às drogas, dependência econômica $\mathrm{e}$ afetiva do traficante, ameaças, desemprego, necessidade de meios para prover o sustento familiar e a obtenção de poder, também têm encontrado associação com o envolvimento e a permanência das mulheres no tráfico de drogas. Pesquisa realizada em 2010 com mulheres encarceradas, encontrou que $66,9 \%$ destas tinham ou já tiveram um ou mais familiar preso por tráfico de drogas, incluindo o companheiro ${ }^{14,15}$.

O presente estudo teve por objetivo estimar a prevalência e os fatores associados à violência física, psicológica e sexual, sofrida por mulheres encarceradas pelo tráfico de drogas nos 24 meses anteriores ao encarceramento numa penitenciária do Estado de Pernambuco.

\section{Método}

Foi realizado um estudo observacional, descritivo do tipo corte transversal, estruturado a partir de amostra aleatória, constituída por mulheres encarceradas por tráfico de drogas na Colônia Penal Feminina do Recife (CPFR), no período de janeiro a março de 2012.

Para o cálculo do tamanho amostral foi estabelecida frequência de violência contra a mulher (VCM) esperada de 27,5\%, com base em um estudo de VCM realizado no Nordeste Brasileiro ${ }^{16}$, utilizando-se o Statcalc do programa Epi-Info versão 3.5.3. Empregando uma precisão relativa de $10 \%$, obteve-se uma amostra de 290 mulheres para um nível de confiança de 95\%. Incluíram-se no estudo mulheres com até doze meses de encarceramento no período da coleta de dados para prevenir viés de recordação e confundimento.

Na realização da coleta de dados participaram a pesquisadora principal e uma acadêmica do curso médico, previamente treinadas para esse fim, comparecendo à CPFR/Recife $(\mathrm{PE})$ regularmente, durante o horário de expediente diurno. As entrevistas, com duração media de 30 minutos cada, foram realizadas no mesmo local, em espaço privativo denominado "parlatório". Foi garantida a confidencialidade e o sigilo das informações. 
Foram empregados parâmetros do Instituto Brasileiro de Geografia e Estatística (IBGE) ${ }^{17}$ para a classificação da cor da população estudada e a Lei de Diretrizes e Bases da Educação Nacional ${ }^{18}$ para definição da escolaridade.

$\mathrm{Na}$ análise dos dados socioeconômicos e demográficos foram utilizadas as seguintes variáveis: idade, cor autodeclarada, escolaridade, nacionalidade, estado civil, companheiro(a) coabitante, número de filhos, procedência, religião, atividade remunerada antes do encarceramento, renda mensal, violência presenciada ou sofrida na adolescência.

As variáveis de análise para prevalência de violência sofrida nos 24 meses que antecederam o encarceramento foram: física (sim/não), psicológica ( $\operatorname{sim} /$ não), sexual (sim/não) e perpetradas pelo companheiro (sim/não).

Para caracterizar a relação das mulheres com o tráfico de drogas utilizou-se as variáveis: uso de drogas (sim/não); idade de ingresso no tráfico ( $\leq 18$ anos e $>18$ anos completos); motivação para participação no tráfico de drogas (dinheiro, parentes no tráfico, acesso fácil às drogas, dependência do traficante, desemprego, ameaças, amizade com pessoas envolvidas no tráfico); tempo de envolvimento ( $<4$ anos e $\geq 4$ anos); condições do encarceramento (aguardando parecer da justiça, aguardando julgamento ou transferência, em cumprimento de sentença).

A seleção das participantes foi realizada através de cadastro fornecido pela CPFR e priorizou-se entrevistar as mulheres com data mais recente do encarceramento, para que não houvesse perdas por transferência para outra unidade prisional, liberdade provisória, habeas corpus ou revogação de prisão preventiva. Todas as mulheres foram devidamente informadas e esclarecidas quanto à voluntariedade da participação e liberdade para retirar o consentimento a qualquer momento durante o período de realização da pesquisa sem qualquer prejuízo, sobretudo para sua condição jurídica.

$\mathrm{Na}$ ausência de instrumento específico para investigar violência em mulheres encarceradas, utilizou-se um questionário com perguntas fechadas e semiabertas para a coleta de dados. As perguntas foram formuladas considerando-se os conceitos da $\mathrm{OMS}^{6}$ e do Ministério da Saúde do Brasil ${ }^{1}$ para violências física, psicológica e sexual.

A análise estatística dos dados foi realizada pelo programa de domínio público EpiInfo 3.5.3. Após dupla digitação, os dados foram checados para consistência e identificação de valores não esperados. As características da amostra foram descritas utilizando-se medidas de tendência central, dispersão e distribuições de frequências para as variáveis quantitativas e qualitativas, respectivamente. Para determinar a associação e a intensidade entre as variáveis de exposição e resposta, foram utilizados os testes qui-quadrado e exato de Fisher, quando pertinente, a um nível de significância de 5\%. Empregou-se análise multivariada pelo modelo de regressão logística múltipla, para entrada das variáveis socioeconômicas e demográficas, prevalência de violência nos 24 meses antes do encarceramento e características do envolvimento da mulher com o tráfico de drogas.

A análise univariada apresentou as variáveis: idade, estado civil, companheiro(a) coabitante, procedência e violência presenciada ou sofrida na adolescência, inicialmente $\operatorname{com} p \leq 0,20$ para associação com a variável de desfecho, sofreu violência nos 24 meses antes do encarceramento. No último bloco de análise permaneceram associadas ao desfecho as variáveis com valor $(p<$ $0,05)$ de significância. Realizou-se o modelo de regressão logística múltipla, método stepwise, para a seleção das variáveis como referencial para o ajuste de fatores de confundimento.

Cinco mulheres não concordaram em participar do estudo e foram substituídas conforme os critérios de elegibilidade: mulheres encarceradas por tráfico de drogas, com até um ano de encarceramento na CPFR, no período da coleta de dados.

O estudo foi aprovado pelo Comitê de Ética em Pesquisa em Seres Humanos do Instituto de Medicina Integral Prof. Fernando Figueira (IMIP). Todas as mulheres que concordaram com a participação assinaram o Termo de Consentimento Livre e Esclarecido (TCLE).

\section{Resultados}

Investigou-se a associação de todas as variáveis socioeconômicas e demográficas, categorizadas em binárias, com sofrer violência nos 24 meses antes do encarceramento, empregando-se análise bivariada.

Evidenciou-se associação entre o estado civil solteira/separada valor $(p=0,04)$ e ter presenciado ou sofrido violência na adolescência valor $(p$ $<0,001)$. As variáveis socioeconômicas e demográficas idade, cor, escolaridade, nacionalidade, companheiro(a) coabitante, número de filhos, procedência, religião, atividade remunerada antes do encarceramento e renda mensal não apresentaram associação significante com o desfecho. (Tabela 1) 


\begin{tabular}{|c|c|c|c|c|c|c|c|c|}
\hline \multirow[t]{42}{*}{ 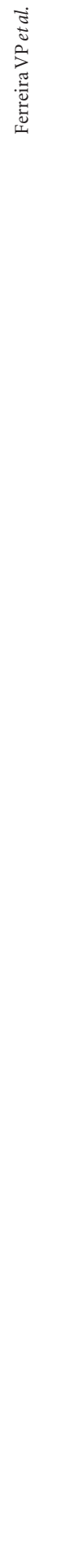 } & $\begin{array}{l}\text { Tabela 1. Distribuição de frequências das caracter } \\
\text { na adolescência de mulheres presas por tráfico de } \\
\text { encarceramento. CPFR/Recife (2012). }\end{array}$ & $\begin{array}{r}\text { ísticas } \\
\text { droga }\end{array}$ & sociode & $\begin{array}{l}\text { nográfi } \\
\text { reram }\end{array}$ & $\begin{array}{l}\text { cas e vic } \\
\text { violênci }\end{array}$ & $\begin{array}{l}\text { olência prese } \\
\text { a nos } 24 \text { mes }\end{array}$ & $\begin{array}{l}\text { ciada/s } \\
\text { es antes }\end{array}$ & $\begin{array}{l}\text { frida } \\
\text { lo }\end{array}$ \\
\hline & \multirow{2}{*}{ Características } & \multicolumn{7}{|c|}{$\begin{array}{c}\text { Violência sofrida nos } 24 \text { meses anteriores ao } \\
\text { encarceramento }\end{array}$} \\
\hline & & $\mathrm{N}$ & $\%$ & $\mathbf{N}$ & $\%$ & IC 95\% & $\mathbf{R P}$ & $\mathbf{p}^{*}$ \\
\hline & Idade (em anos completos) & & & & & $0,98-1,69$ & 1,29 & 0,07 \\
\hline & $\leq 25$ & 79 & 49,1 & 82 & 50,9 & & & \\
\hline & $>25$ & 49 & 38,0 & 80 & 62,0 & & & \\
\hline & Cor & & & & & $0,89-1,60$ & 1,19 & 0,23 \\
\hline & Branca & 31 & 50,8 & 30 & 49,2 & & & \\
\hline & Preta e parda & 97 & 42,4 & 132 & 57,6 & & & \\
\hline & Escolaridade (anos completos) & & & & & $0,80-1,73$ & 1,17 & 0,38 \\
\hline & $\leq 9$ & 106 & 46,1 & 124 & 53,9 & & & \\
\hline & $>9$ & 18 & 39,1 & 28 & 60,9 & & & \\
\hline & Procedência & & & & & $0,89-1,77$ & 1,26 & 0,16 \\
\hline & Recife e RMR & 103 & 46,4 & 119 & 53,6 & & & \\
\hline & Interior de PE e outros Estados & 25 & 36,8 & 43 & 63,2 & & & \\
\hline & Estado civil & & & & & $0,43-0,88$ & 0,62 & 0,04 \\
\hline & Solteira/separada & 117 & 42,7 & 157 & 57,3 & & & \\
\hline & Casada/união estável & 11 & 68,6 & 05 & 31,2 & & & \\
\hline & Companheiro(a) & & & & & $0,90-1,57$ & 1,19 & 0,21 \\
\hline & $\operatorname{Sim}$ & 85 & 47,0 & 96 & 53,0 & & & \\
\hline & Não & 43 & 39,4 & 66 & 60,6 & & & \\
\hline & Coabitação & & & & & $0,89-1,64$ & 1,21 & 0,20 \\
\hline & Sim & 65 & 48,5 & 69 & 51,5 & & & \\
\hline & Não & 36 & 40,0 & 54 & 60,0 & & & \\
\hline & Filhos & & & & & $0,81-1,73$ & 1,18 & 0,35 \\
\hline & Sim & 109 & 45,2 & 131 & 54,8 & & & \\
\hline & Não & 19 & 38,0 & 31 & 62,0 & & & \\
\hline & Número de Filhos & & & & & $0,70-1,70$ & 1,09 & 0,67 \\
\hline & $\leq 4$ & 96 & 45,9 & 113 & 54,1 & & & \\
\hline & $>4$ & 13 & 41,9 & 18 & 58,1 & & & \\
\hline & Atividade remunerada & & & & & $0,84-1,49$ & 1,11 & 0,43 \\
\hline & Sim & 86 & 45,2 & 103 & 54,8 & & & \\
\hline & Não & 42 & 40,4 & 59 & 59,6 & & & \\
\hline & Rendimento mensal (em SM) & & & & & $0,65-1,23$ & 0,90 & 0,53 \\
\hline & $\leq 1$ & 53 & 44,5 & 66 & 55,5 & & & \\
\hline & $>1$ & 33 & 49,3 & 34 & 50,7 & & & \\
\hline & Religião & & & & & $0,84-1,46$ & 1,11 & 0,43 \\
\hline & Sim & 82 & 46,0 & 95 & 54,0 & & & \\
\hline & Não & 46 & 41,3 & 64 & 58,7 & & & \\
\hline & Violência presenciada ou sofrida na adolescência & & & & & $1,23-1,68$ & 1,44 & $<0,001$ \\
\hline & Sim & 105 & 82,0 & 23 & 18,0 & & & \\
\hline & Não & 92 & 56,8 & 70 & 43,2 & & & \\
\hline
\end{tabular}

n: amostra; \%: proporção; IC: índice de confiança; RP: razão de prevalência. SM = salário mínimo vigente: R\$622,00. *Teste qui-quadrado.

Nos 24 meses que antecederam ao encarceramento de mulheres por tráfico de drogas na CPFR, $128(44,1 \%)$ relataram ter sofrido algum tipo de violência. As violências físicas sofridas foram $35,2 \%$, as psicológicas $31,8 \%$ e as sexuais $3,8 \%$. De um total de 206 relatos de agressões sofridas por companheiros, genitores, pais adotivos, outros familiares ou outras pessoas, identificou-se o companheiro como o perpetrador mais frequente, com $44,1 \%$ dos casos. (Tabela 2 )

Na relação com o tráfico de drogas, encontraram-se $47,3 \%$ de mulheres que fizeram uso de 
drogas lícitas e/ou ilícitas. A maior parte entrou para o tráfico de drogas com idade inferior a 18 anos e apesar de todas terem sido encarceradas pelo mesmo motivo, $67,5 \%$ participaram efetivamente do tráfico de drogas desenvolvendo pa-

Tabela 2. Distribuição de frequências dos tipos de violências sofridas por mulheres presas por tráfico de drogas que sofreram violência nos 24 meses antes do encarceramento e perpetrador. CPFR/ Recife (2012).

\begin{tabular}{lcr}
\hline \multicolumn{1}{c}{ Variáveis } & n & \% \\
\hline Violência sofrida nos 24 meses antes & 128 & 44,1 \\
do encarceramento & & \\
$\quad$ Violência Física & 95 & 35,2 \\
$\quad$ Violência Psicológica & 92 & 31,8 \\
$\quad$ Violência Sexual & 11 & 3,8 \\
Violências perpetradas pelo & 91 & 44,1 \\
companheiro (n $=206)$ & & \\
\hline
\end{tabular}

péis como: traficante, transportadora ou guardadora. Relataram o dinheiro como o principal motivo $(40,7 \%)$ para o ingresso no tráfico. O tempo de envolvimento foi menor que quatro anos para $38,8 \%$ das mulheres e $42,9 \%$ ainda aguardavam encarceradas o parecer da justiça sobre sua condição penal. (Tabela 3 )

Após análise multivariada pelo modelo de regressão logística múltipla, as variáveis que permaneceram associadas ao desfecho foram estado civil solteira/separada valor $(\mathrm{p}=0,03)$ e presenciou ou sofreu violência na adolescência valor $(\mathrm{p}<0,001)$. (Tabela 4)

\section{Discussão}

Identificar prevalência de violência em mulheres encarceradas por tráfico de drogas numa cidade do Nordeste foi um desafio, considerando-se a escassez de estudos nessa área. Nos últimos cin-

Tabela 3. Mulheres que sofreram violência nos 24 meses antes do encarceramento e características do envolvimento no tráfico de drogas. CPFR/Recife (2012).

\begin{tabular}{|c|c|c|}
\hline \multirow{2}{*}{ Variáveis } & \multicolumn{2}{|c|}{ Sofreram violência } \\
\hline & $\mathrm{n}=128$ & $\%$ \\
\hline Usou drogas & 78 & 60,9 \\
\hline Participou do tráfico de drogas & 87 & 67,5 \\
\hline \multicolumn{3}{|l|}{ Idade de ingresso no tráfico de drogas em anos completos } \\
\hline$\leq 18$ & 36 & 41,4 \\
\hline$>18$ & 51 & 58,6 \\
\hline \multicolumn{3}{|l|}{ Motivação para participar do tráfico } \\
\hline Dinheiro & 35 & 47,9 \\
\hline Parentes no tráfico, fácil acesso às drogas, outras ${ }^{*}$ & 38 & 52,1 \\
\hline \multicolumn{3}{|l|}{ Tempo de envolvimento no tráfico de drogas (em anos de participação) } \\
\hline$<4$ & 50 & 58,7 \\
\hline$\geq 4$ & 37 & 41,3 \\
\hline \multicolumn{3}{|l|}{ Situação jurídica } \\
\hline Aguardava parecer da justiça & 93 & 72,7 \\
\hline Aguardava julgamento ou transferência ou cumpria sentença & 35 & 27,3 \\
\hline
\end{tabular}

n: amostra; \%: proporção; * dependência do traficante, desemprego, ameaças, amizade com pessoas do tráfico.

Tabela 4. Características associadas a sofrer violência nos 24 meses antes do encarceramento e o tráfico de drogas após análise multivariada. CPFR/Recife (2012).

\begin{tabular}{|c|c|c|c|}
\hline Características & Risco ajustado (odds ratio) & IC95\% & p \\
\hline Estado civil solteira/separada & 3,53 & $1,13-11,06$ & 0,03 \\
\hline Presenciou/sofreu violência na adolescência & 0,27 & & $<0,001$ \\
\hline Constante & & $0,15-0,48$ & 0,88 \\
\hline
\end{tabular}

RP: risco ajustado; IC: índice de confiança; $p$ : significância da amostra. 
co anos, o tráfico de drogas representou $60 \%$ do encarceramento feminino no Brasil ${ }^{19}$, e a frequência de 44,1\% de violência sofrida nos 24 meses anteriores ao encarceramento na CPFR é considerada elevada quando comparada a estudo realizado em serviços terciários de saúde no Nordeste brasileiro ${ }^{16}(27,5 \%)$, cuja clientela pertencia ao Sistema Único de Saúde (SUS).

O perfil socioeconômico e demográfico demonstrou maior frequência de mulheres com até 25 anos, solteiras, com filhos e baixa escolaridade. Estes achados foram semelhantes aos de estudos que incluiu mulheres presidiárias no Nordeste do Brasil $^{20} \mathrm{e}$ da população carcerária feminina em Minas Gerais ${ }^{21}$.

Na Região Nordeste, dados do Censo demográfico/2010 22 evidenciaram uma frequência de $15,1 \%$ de unidades domésticas nucleares monoparentais femininas, compostas por mães com filhos. No presente estudo, $85,8 \%$ das mulheres eram solteiras ou separadas e tinham filhos, legitimando a mudança do papel social de esposa e mãe, tradicionalmente associado às mulheres, para provedora do lar com acúmulo de várias responsabilidades e funções.

A presença de 78,9\% de mulheres não brancas no estudo foi um dado que diferiu dos achados de estudo com enfoque na história penal da população encarcerada feminina, realizado no interior de São Paulo ${ }^{11}$, que encontrou maioria de cor branca. É possível que diferentes resultados se expliquem pela variada presença/ausência de brancos e/ou afrodescendentes nas várias regiões brasileiras, que indica $77,7 \%$ de brancos na região sul. Considerando-se que $51 \%$ da população brasileira é feminina ${ }^{17}$, este achado é indicativo de elevada frequência de mulheres afrodescendentes na população carcerária feminina no nordeste do Brasil.

A baixa escolaridade das mulheres participantes deste estudo foi concordante com os dados do Sistema Integrado de Informações Penitenciárias (InfoPen) do Ministério da Justiça do Brasi $^{23}$, que evidenciou maioria de mulheres encarceradas com ensino fundamental incompleto. Embora os dados do InfoPen indiquem uma melhoria do nível de escolaridade em relação ao período anterior à implantação da Lei de Execuções Penais ${ }^{24}$, nossos resultados apontam para uma possível baixa efetividade desta Lei, considerando que mulheres encarceradas com baixa ou nenhuma escolaridade ainda são maioria em unidades prisionais no Estado do Pernambuco.

Recife e sua Região Metropolitana foram os locais de maior procedência das mulheres encar- ceradas $(76,55 \%)$, resultados semelhantes foram mostrados em estudos realizados em outras regiões brasileiras ${ }^{11,21,25}$. É possível que o crescimento econômico das regiões metropolitanas e capitais de Estados intensifique o comércio de drogas ilícitas e facilite o acesso a estas, constituindo-se um potencial atrativo para maior envolvimento da população no tráfico de drogas ${ }^{26}$. Ademais, com o crescimento econômico, os empregos ficam mais selecionados, amplia-se a necessidade de maior especialização profissional, fato que exclui uma parte populacional significante e favorece o desemprego.

A baixa renda mensal das mulheres deste estudo, inferior a um salário mínimo, refletem a condição de vida da população em situação de exclusão social, na qual prevalecem o subemprego e a baixa renda, sendo consensual em estudos incluindo população carcerária brasileira ${ }^{21,22,25}$. A falta de perspectiva e o desemprego fortalecem a atividade econômica ligada ao tráfico de drogas no Brasil porque criam oportunidade de lucro às pessoas sem acesso ao mercado de trabalho formal ${ }^{27}$.

Os estudos ainda são escassos quando se trata de violência sofrida por mulheres em períodos anteriores ao encarceramento. Populações do sistema prisional são frequentemente excluídas dos inquéritos nacionais de saúde, que tendem a uma sub-representação de grupos marginalizados ${ }^{28}$.

As elevadas prevalências de violência física (35\%) e violência psicológica (32\%) na população estudada, e a indicação do companheiro como o principal perpetrador destas violências (44\%), assemelham-se às encontradas em estudo sobre violência praticada por parceiro íntimo em regiões do Brasil ${ }^{29}$ e em área urbana economicamente vulnerável de Brasília (DF) ${ }^{30}$.

Este estudo mostrou uma baixa prevalência de violência sexual $(3,8 \%)$ se comparado a achados de estudo brasileiro sobre violência contra a mulher por parceiro íntimo ${ }^{30}$, que encontrou $28,8 \%$ de violência sexual ao longo da vida e estudos recentes incluindo mulheres encarceradas em prisões de Nova Gales do Sul e Queensland, com cerca de $60 \%$ das participantes que autorreferiram coerção sexual antes de encarceramento, considerando fatores de risco: identidade homo e bissexual, desemprego, estado civil solteira/separada, prostituição e uso de drogas ${ }^{28}$ e estudo de prevalência de exposição à violência física e sexual em população baseada em rua de Tegucigalpa, Honduras ${ }^{31}$. Resultados tão distintos podem apontar na direção do não reconhecimento da prática sexual não consensual como uma vio- 
lência e a naturalização da violência em suas vidas, estabelecida pelos registros "comuns" e frequentes de violências presenciadas e sofridas na adolescência da maioria destas mulheres.

Embora informações em relação à violência por parceiro íntimo careçam de exatidão, dados deste estudo indicam que a mulher ainda é mantida numa posição de subalternidade e domínio do sexo masculino, que usa de violência como forma de dominação e que as agressões acontecem no próprio lar. Afora esses achados, deve-se considerar a presença constante de fatores de risco para violência associados à exclusão social, política e econômica que inclui esse grupo particular e vulnerável de mulheres ${ }^{32}$.

Houve elevada prevalência para os fatores de risco relacionados ao tráfico de drogas. O dinheiro representou a condição necessária para a mulher manter e proteger os que estão sob sua responsabilidade. Na perspectiva da mulher como cuidadora, o dinheiro, não importando sua origem ilegal, possibilita a manutenção da sua família.

A sensação de poder e o status experimentados por pessoas envolvidas com o tráfico de drogas também foram mencionados como motivadores para o ingresso nessa atividade ilegal. Estudos envolvendo população carcerária feminina no Nordeste e Sudeste do Brasil ${ }^{33,34}$ corroboram essa realidade. É a relação de gênero que fundamenta a participação das mulheres no tráfico de drogas, representando uma possibilidade de conferir a elas um poder reconhecido apenas aos homens. Invisíveis socialmente, constroem suas identidades criminosas como forma de resistência à posição marginalizada, na tentativa de se aproximarem dos homens e do poder usualmente associado a eles ${ }^{35}$.

O tempo de envolvimento com o tráfico de drogas, menor que quatro anos, é um forte indicador de que a vida no mundo do crime é curta, vez que o afastamento das atividades que envolvem o tráfico de drogas frequentemente ocorre pelo encarceramento das mulheres, dado ratificado pelo crescimento dessa situação nos últimos dez anos em decorrência do tráfico de dro$\operatorname{gas}^{13,19,35}$.

$\mathrm{O}$ alto índice de mulheres em condição de sumariadas $(93,4 \%)$ reforça dados do Ministério Público de Pernambuco $(\mathrm{MPP})^{36}$, referentes à morosidade da justiça no julgamento dos processos penais, acarretando superlotação nas unidades prisionais de mulheres a espera de julgamento, sentença, autorização de transferência para outra Instituição ou simplesmente um parecer jurídico. Torna-se relevante destacar que a população carcerária do presente estudo foi superior a quase o triplo das 150 vagas que compõem a capacidade instalada da CPFR. Dados que mostram a necessidade de um posicionamento das instâncias jurídicas para dar consonância à finalidade primordial da pena privativa de liberdade, que é a ressocialização da população carcerária, com estrita atenção à sua dignidade.

Há carência de pesquisas relacionando o uso de drogas à violência contra as mulheres e não há consenso se o mesmo provoca um cenário de violência. Entretanto, é reconhecido o risco social causado pelo uso e tráfico de drogas ilícitas para a população em geral, e para as mulheres e seus filhos e filhas, em particular.

O encarceramento de mulheres em decorrência do tráfico de drogas é fato preocupante, considerando a velocidade com que esse crime vem se expandindo no Brasil e no mundo e suas consequências para a sociedade. Entretanto, para explicar o envolvimento dessa população no tráfico de drogas, não se pode afirmar que uma única causa o determine ou que variáveis isoladas alcancem a magnitude do problema. Faz-se necessário conhecer o conjunto de fatores que o definem, considerando um contexto que inclui os aspectos cultural, econômico e social que fomenta as desigualdades de gênero e, consequentemente, a violência contra a mulher, sendo essencial analisá-los sob o olhar do respeito aos direitos humanos.

É importante destacar que, em algumas condições, nossos resultados não demonstraram associação significante, possivelmente pelas limitações metodológicas dos estudos observacionais descritivos ou mesmo pela metodologia utilizada para a coleta da amostra. Contudo, as elevadas prevalências de fatores de risco para sofrer violência encontradas na presente pesquisa, são apoiadas por outros estudos de prevalência de violência contra a mulher por parceiro íntimo realizados no Brasil2 ${ }^{29,30}$.

Este estudo permitiu conhecer as dificuldades do sistema público pernambucano para enfrentar e prevenir problemas de tamanha grandeza e importância para a saúde publica. Recomenda-se a realização de ações coletivas de educação em saúde na CPFR e para populações carcerárias em geral, visto que podem possibilitar o desenvolvimento de habilidades para identificar situações de risco à vitimização por violência, compreendendo assim o desenvolvimento do potencial de resiliência dessas mulheres, mesmo quando participantes do tráfico de drogas e ex- 
postas às várias formas de violência inerentes às atividades de risco. Informadas e cientes de tais riscos, elas poderão adotar medidas de prevenção à violência contra si próprias e melhorar a qualidade de vida nas penitenciárias.

\section{Conclusão}

Os resultados do presente estudo mostraram elevada prevalência de violências física e psicológica nos 24 meses antes do encarceramento de mulheres por tráfico de drogas na CPFR e indicaram o companheiro como o perpetrador mais frequente. Verificou-se o uso e o tráfico de drogas como fatores associados a sofrer violência no mesmo período, aumentando sua prevalência nas mulheres solteiras/separadas e que a presenciaram ou a sofreram na adolescência. O perfil mostrou maioria de mulheres jovens, não brancas, chefes de família, com baixa escolaridade e renda e que entraram para o tráfico de drogas para ganhar dinheiro e cuidar da família. Esses achados justificam a necessidade de se promover, junto às mulheres, ações que auxiliem na prevenção de comportamentos de risco para a violência e na inserção em atividades ilegais como o tráfico de drogas, o que lhes proporcionará uma vida mais segura.

\section{Colaboradores}

VP Ferreira trabalhou na elaboração, concepção e na redação final; MA Silva participou da concepção e da redação; CN Neto trabalhou na metodologia; Neto GHF contribuiu na concepção do texto; CV Chaves e RP Bello trabalharam na pesquisa. 


\section{Referências}

1. Brasil. Ministério da Saúde (MS). Norma técnica sobre prevenção e tratamento dos agravos resultantes da violência sexual contra mulheres e adolescentes. Brasília: MS; 2005.

2. Schraiber LB, Oliveira AFPL, Couto MT. Violência e saúde: estudos científicos recentes. Rev Saude Publica 2006; 40(N Esp.):112-120.

3. Azambuja MPR, Nogueira C. Introdução à violência contra as mulheres como um problema de direitos humanos e de saúde pública. Saúde Soc 2008; 17(3):101-112.

4. Minayo MCS. A inclusão da violência na agenda da saúde: trajetória histórica. Cien Saude Colet 2007; 11(Supl.):1259-1267.

5. Schraiber LB, Oliveira AFPL, Couto MT. Violência e saúde: contribuições teóricas, metodológicas e éticas de estudos da violência contra a mulher. Cad Saude Publica 2009; 25(Supl. 2):S205-S216.

6. Organização Mundial de Saúde (OMS). Relatório Mundial sobre Violência e Saúde. Violência: um problema mundial de saúde pública. Genebra: OMS; 2002.

7. Presser AD, Meneghel SN, Hennington EA. Mulheres enfrentando as violências: a voz dos operadores sociais. Saúde Soc 2008; 17(3):126-137.

8. Silva MA, Neto GHF, Figueiroa JN, Filho JEC. Maus tratos na infância de mulheres vítimas de violência. Psicologia em Estudo 2009; 14(1):121-127.

9. Ely A, Cechine 1B, Camargo M. Entre vítimas e criminosas: estudo sobre o histórico de violência na vida das mulheres em situação de detenção no presídio Santa Augusta, Criciúma-SC. Seminário de Ciências Sociais Aplicadas 2010; 2:2.

10. Silva LS, Menezes MLN, Lopes CLA, Corrêa MSM. Anos potenciais de vida perdidos por mulheres vítimas de homicídio na cidade do Recife, Pernambuco, Brasil. Cad Saude Publica 2011. 27(9):17211730 .

11. Scherer ZAP, Scherer EA, Nascimento AD, Ragozo FD. Perfil sociodemográfico e história penal da população encarcerada de uma penitenciária feminina do interior do Estado de São Paulo. SMAD 2011; 7(2):55-62.

12. Faria AAC, Barros VA. Tráfico de drogas: uma opção entre escolhas escassas. Psicologia e Sociedade 2011; 23(3):536-544

13. Brasil. Ministério da Justiça (MJ). Departamento Penitenciário Nacional (DEPEN). Mulheres Encarceradas, Diagnóstico Nacional. Crescimento da População Carcerária. Brasília: MJ; 2008.

14. Souza KOJ. A Pouca Visibilidade da Mulher Brasileira no Tráfico de Drogas. Psicologia em Estudo 2009; 14(4):649-657.

15. Lopes RMF, Mello DC, Lima II. Mulheres Encarceradas e Fatores Associados a Drogas e Crimes. Ciências \& Cognição 2010; 15(2):121-113.

16. Silva MA, Neto GHF, Figueiroa JN, Filho JEC. Violence against women: prevalence and associated factors in patients attending a public healthcare service in the Northeast of Brazil. Cad Saude Publica 2010; 26(2):264-272
17. Instituto Brasileiro de Geografia e Estatística (IBGE) Características étnico-raciais da população. 2008. [acessado 2012 jun 6]. Disponível em: http://www.ibge. gov.br/home/estatistica/populacao/caracteristicas raciais/PCERP2008.pdf

18. Brasil. Lei no 9.394 de 20 de dezembro de 1996. Estabelece as diretrizes e bases da educação nacional. Diário Oficial da União 1996; 23 dez.

19. Brasil. Ministério da Justiça. Sistema Integrado de Informacões Penitenciárias (INFOPEN). Mulheres Presas - Dados Gerais, 2011. [acessado 2014 maio 23]. Disponível em: http://portal.mj.gov.br/data/ Pages/MJD574E9CEITEMID598A21D892E444 B5943A0AEE5DB94226PTBRIE.htm

20. Nicolau AIO, Ribeiro SG, Lessa PRA, Monte AS, Ferreira RCN, Pinheiro AKB. Retrato da realidade socioeconômica e sexual de mulheres presidiárias. Acta Paul Enferm 2012; 25(3):386-392.

21. Bastos PRS. Criminalidade feminina: estudo do perfil da população carcerária feminina da Penitenciária Professor Ariosvaldo de Campos Pires - Juiz de Fora (MG). Rev. Âmbito Jurídico 2010; XIII(81).

22. Instituto Brasileiro de Geografia e Estatística (IBGE). Censo Demográfico 2010. Indicadores Sociais Municipais. Composição das unidades domésticas. [acessado 2012 nov 15]. Disponível em: http://www.ibge. gov.br/home/estatistica/populacao/censo2010/ indicadores sociais municipais/indicadores sociais_municipais.pdf

23. Brasil. Ministério da Justiça (MJ). Departamento Penitenciário Nacional (DEPEN). Relatórios estatísticos do Sistema integrado de informações Penitenciárias. 2011. [acessado 2012 out 29]. Disponível em: http://portal.mj.gov.br/data/Pages/MJC4D50E DBPTBRNN.htm

24. Brasil. Lei 7.210, de 11 de julho de 1984. Lei de execuções penais. Diário Oficial da União 1984; 13 jul.

25. Scherer ZAP, Scherer EA. Concepções e vivências de mulheres encarceradas sobre a violência. Cogitare Enferm 2009; 14(3):435-440.

26. Haesbaert R. Dos múltiplos territórios à multiterritorialidade. O mito da desterritorialização. Niterói: UFF; 2004.

27. Organização das Nações Unidas (ONU). Comissão de Narcóticos das Nações Unidas. Escritório das Nações Unidas sobre Drogas e Crime (UNODC). Relatório da Comissão de Viena; 2009. [acessado 2012 out 30]. Disponível em: http://www.unodc.org/ unodc/en/commissions/CND/session/52.htm

28. Malacova E, Butler T, Yap L, Grant L, Richards A Smith AM, Donovan B. Sexual coercion prior to imprisonment: prevalence, demographic and behavioural correlates. Int J STD AIDS 2012; 23(8):533539.

29. Schraiber LB, D’Oliveira AFPL, França-Junior I, Diniz S, Portella, Ludemir AB, Valença O, Couto MT. Prevalência da violência contra a mulher por parceiro íntimo em regiões do Brasil. Rev Saude Publica 2007; 41(5):797-807. 
30. Moura LBA, Gandolfi L, Nogales AM, Pratesi R. Violências contra mulheres por parceiro íntimo em área urbana economicamente vulnerável, Brasília/ DF. Rev Saude Publica 2009; 43(6):944-953.

31. Navarro JR, Cohen J, Arechaga ER, Zuniga E. Physical and sexual violence, mental health indicators, and treatment seeking among street-based population groups in Tegucigalpa, Honduras. Rev Panam Salud Publica 2012; 31(5):388-395.

32. Moraes PAC, Dalgalarrondo P. Mulheres encarceradas em São Paulo: saúde mental e religiosidade. $J$ Bras Psiquiatria 2006; 55(1):50-56.

33. Barcinski M. Protagonismo e vitimização na trajetória de mulheres envolvidas na rede do tráfico de drogas no Rio de Janeiro. Cien Saude Colet 2009; 14(2):577-586.

34. Barcinski M. Centralidade de gênero no processo de construção da identidade de mulheres envolvidas na rede do tráfico de drogas. Cien Saude Colet 2009; 14(5):1843-1853.

35. Barcinski M. Mulheres no Tráfico de Drogas: a criminalidade como estratégia de saída da invisibilidade social feminina. Contextos Clínicos 2012; 5(1): 52-61.

36. Pernambuco. Ministério Público de Pernambuco (MPP). Cidadania em ação. [acessado 2012 jun 29]. Disponível em: http://www.mp.pe.gov.br

Artigo apresentado em 22/04/2013

Aprovado em 12/06/2013

Versão final apresentada em 22/06/2013 